\title{
Changes of outer retinal microstructures after photodynamic therapy for chronic central serous chorioretinopathy
}

This article was published in the following Dove Press journal:

Clinical Ophthalmology

16 August 2017

Number of times this article has been viewed

\author{
Kimiko Shimizu' \\ Yohei Hashimoto' \\ Keiko Azuma' \\ Yoko Nomura' \\ Ryo Obata' \\ Hidenori Takahashi, ${ }^{1,2}$ \\ Yasuo Yanagi ${ }^{3,4}$ \\ 'Department of Ophthalmology, \\ Graduate School of Medicine and \\ Faculty of Medicine, University \\ of Tokyo, Tokyo, ${ }^{2}$ Department \\ of Ophthalmology, Jichi Medical \\ University, Tochigi, Japan; ${ }^{3}$ Singapore \\ Eye Research Institute, Singapore \\ National Eye Center, ${ }^{4}$ Ophthalmology \\ and Visual Sciences Program, Duke- \\ NUS Medical School, National \\ University of Singapore, Singapore
}

Purpose: To evaluate the morphological changes in retinal microstructures following modified photodynamic therapy (PDT) for chronic central serous chorioretinopathy.

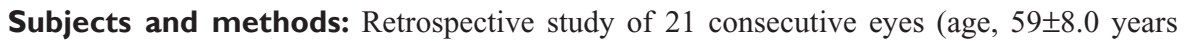
$[$ mean $\pm \mathrm{SD}]$ ) of 21 patients with chronic central serous chorioretinopathy. Inner foveal thickness (the distance between the internal limiting membrane and external limiting membrane), photoreceptor outer segment (PROS) length at the point without serous retinal detachment and choroidal thickness were assessed with enhanced depth imaging optical coherence tomography before treatment and at 1,3 and 6 months after modified PDT.

Results: Six eyes had half-dose and 15 eyes had half-fluence PDT. PROS length within the irradiated area was significantly decreased by $3.9 \%$ at 1 month compared with that before modified PDT (43.5 \pm 5.72 and 40.5 $\pm 7.53, P=0.020$ [paired $t$-test]) and returned to baseline length at 3 and 6 months (43.0 \pm 5.42 and $43.5 \pm 4.33 \mu \mathrm{m}$ [mean $\pm \mathrm{SD}$ ]; $P=0.53$ and 1.00 [paired $t$-test]). PROS length of the nonirradiated area at 1, 3 and 6 months after modified PDT did not significantly differ from that before PDT $(41.8 \pm 6.35,41.4 \pm 5.33,41.9 \pm 4.67$ and $42.3 \pm 4.26 \mu \mathrm{m}$ [mean $\pm \mathrm{SD}$ ]; $P=0.66,0.90$ and 0.60 , respectively [paired $t$-test]). There was no significant change in inner foveal thickness during the observation period. At all time points, choroidal thickness was significantly thinner than it was before PDT $(P<0.001$, paired $t$-test).

Conclusion: Modified PDT may cause mild temporary microstructural changes.

Keywords: photodynamic therapy, photoreceptor outer segment length, chronic central serous chorioretinopathy, inner foveal thickness, choriocapillaris

\section{Introduction}

Chronic central serous chorioretinopathy (CSC) is characterized by long-term serous retinal detachment (SRD) in the central macular region ${ }^{1,2}$ due to primary disturbance of choroidal circulation. ${ }^{1-3}$ Persistent or recurrent SRD leads to progressive visual loss..$^{4,5}$ The pathogenesis of CSC is not well understood, but some reports have described systemic involvement. 6,7

Since the first report showing the efficacy of photodynamic therapy (PDT) with verteporfin (Visudyne; Novartis AG, Basel, Switzerland) for the treatment of chronic $\mathrm{CSC},{ }^{8}$ several subsequent reports have confirmed its effectiveness, which is through promotion of subretinal fluid (SRF) absorption by reducing choroidal vascular hyperpermeability. Although rare, complications such as retinal pigment epithelium (RPE) changes, excessive choriocapillaris hypoperfusion and secondary choroidal neovascularization (CNV) have been reported. ${ }^{8-12}$ To reduce adverse effects, modified PDT protocols, such as half-fluence/half-dose PDT, have been proposed and are now frequently
Correspondence: Yasuo Yanagi Singapore Eye Research Institute, Singapore National Eye Center, II Third Hospital Avenue 16875I, Singapore Tel +6569881460

Fax +65 62263995

Email yasuo.yanagi@snec.com.sg 
used in the treatment of chronic CSC. ${ }^{13,14}$ While several studies have reported its effectiveness and safety, the influence on photoreceptors has been also reported. ${ }^{15,16}$ However, no studies have demonstrated quantitative change of photoreceptors after modified PDT.

Spectral-domain optical coherence tomography (SD-OCT, Spectralis ${ }^{\circledR}$; Heidelberg Engineering, Heidelberg, Germany) has enabled the investigation of morphological changes to the microstructures of photoreceptors in the retina. Some studies have shown a significant association between the best-corrected visual acuity (BCVA) and the integrity of the ellipsoid zone (EZ, also known as the photoreceptor inner and outer segment junction line) and interdigitation zone (also known as the cone outer segment tips) in CSC. ${ }^{17-19}$ Recently, it was also reported that central photoreceptor outer segment (PROS) length, which refers to the distance between the EZ and the RPE (defined as the most hyperreflective line by ImageJ [National Institutes of Health, Bethesda, MD; available at http://rsbweb.nih.gov]), is strongly correlated with BCVA after idiopathic epiretinal membrane (ERM) surgery and in patients with diabetic macular edema. ${ }^{20,21}$ Thus, PROS length is also considered an important parameter for deducing retinal function.

PDT causes choriocapillaris damage and choroidal vascular remodeling. A number of studies have investigated choroidal structure after PDT, demonstrating decreased choroidal thickness (CT) even after modified PDT. ${ }^{22-25}$ However, only a few qualitative studies, but no quantitative reports, have thoroughly investigated the microstructural changes in the outer retina after modified PDT. Thus, the current study examined PROS length and inner foveal thickness (IFT) to determine the influence on photoreceptors after modified PDT for chronic CSC.

\section{Subjects and methods Patient selection}

Thirty-seven chronic CSC patients underwent their first PDT between May 2012 and July 2014 at Tokyo University Hospital. Among them, 21 were enrolled in the current analysis after excluding the following patients: 1) those who had received previous PDT $(n=1) ; 2)$ those with evidence of $\mathrm{CNV}$ or polypoidal choroidal vasculopathy (PCV) $(n=1) ; 3)$ those who received PDT irradiation covering the extrafoveal region only ( $n=3)$ and 4) those who had smaller area of PDT irradiation than the lesion of SRD $(n=11)$, because we measured PROS length at the point where PDT was irradiated but without SRD, in order to avoid the influence of SRD on photoreceptors. All patients had symptomatic chronic CSC for $\geq 3$ months, and were followed up for at least 6 months after initial PDT. Diagnosis was based on the findings of slit-lamp biomicroscopy, fluorescein angiography (FA), indocyanine green angiography (ICGA) and SD-OCT. BCVA data and SD-OCT images were available from all patients before PDT and at 1, 3 and 6 months after PDT.

\section{Study protocol}

This retrospective study was approved by the Institutional Review Board of the University of Tokyo. All patients provided written consent to review their medical records. BCVA and SD-OCT findings were investigated before and at 1, 3 and 6 months after PDT. BCVA findings were converted to a logarithm of the minimum angle of resolution (logMAR) for statistical analysis. Macular scanning with SD-OCT was performed using both standard and enhanced depth imaging modes, with a width of $6 \mathrm{~mm}$. In SD-OCT images, we assessed the IFT (the distance between the internal limiting membrane [ILM] and the external limiting membrane [ELM]), PROS length (the distance between the EZ and the RPE) and CT. RPE layer was defined using Image J software in the following text.

IFT and PROS length measurements were performed using Image J software V1.48, according to the method of Shiono et al. ${ }^{21}$ Reflectivity of cross-sectional parallel lines was calculated longitudinally within the selected area in grayscale SD-OCT images. SD-OCT scans through the fovea showed 4 clearly distinguishable, highly reflective bands as previously described, representing the RPE, EZ, ELM and ILM. PROS length was measured as the distance between the RPE and the EZ, and IFT as that between the RPE and the ILM. IFT was measured at the fovea, and the PROS length was measured at 2 sections: one within the irradiated area and the other outside. To exclude the influence of SRD, measurements were performed in the area without SRD. In patients that had "follow-up" mode SD-OCT scans, we could choose the same points. In other cases, we selected the same points from the fundus images accompanied with SD-OCT scans at each time point (Figure 1). Examples of the serial changes of PROS length calculated from SD-OCT findings are displayed in Figure 2.

CT was assessed at 3 sections: fovea and 2 points where the PROS length was measured. CT was measured manually with a caliper embedded in the SD-OCT system.

\section{Photodynamic therapy}

Patients received either half-fluence or half-dose PDT with verteporfin. Half-fluence PDT was performed with a $6 \mathrm{mg} / \mathrm{m}^{2}$ dose of verteporfin but with half-fluence of $300 \mathrm{~mW} / \mathrm{cm}^{2}$ for 83 seconds. Half-dose PDT was employed using a 50\% dose of verteporfin $\left(3 \mathrm{mg} / \mathrm{m}^{2}\right)$ with the duration and laser power 


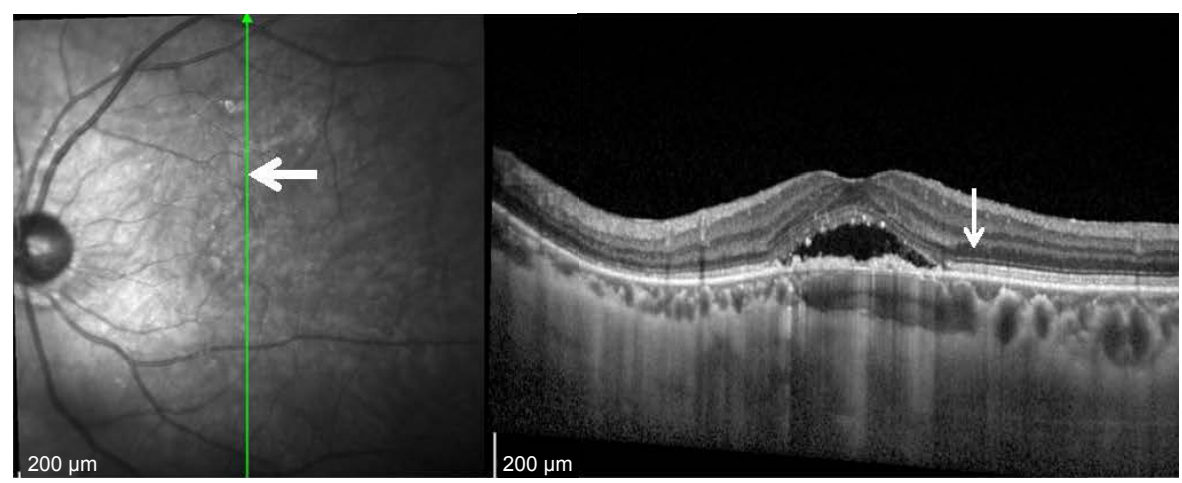

Figure I Thick arrow in the fundus image refers to the same place where thin arrow points to the spectral domain optical coherence tomography scan.

unchanged, and a fluence of $600 \mathrm{~mW} / \mathrm{cm}^{2}$ for 83 seconds. Greatest linear dimension (GLD) was determined with reference to the area of abnormal choroidal circulation, such as hyperpermeability and dilated choroidal vessels, and the area showing RPE breakdown according to the findings of FA and ICGA. We adopted ICGA study in 14 eyes and FA study in 7 eyes, and determined GLD strictly to avoid possible collateral damage. Laser spot size was set as $\sim 500 \mu \mathrm{m}$ plus the GLD, with a maximum size of $50 \mu \mathrm{m}$. Verteporfin was infused over 10 minutes, followed by delivery of diode laser at $689 \mathrm{~nm}$ (Visulas 690S; Carl Zeiss Meditec Inc., Dublin, CA, USA) 15 minutes after the start of infusion. After treatment, all patients were given protective spectacles and instructed to avoid strong light for at least 48 hours.

\section{Statistical analysis}

Serial comparisons of mean BCVA, IFT, PROS length and CT were conducted using the paired $t$-test. JMP software (version 11; SAS institute Inc., Cary, NC, USA) was used for data analysis, and a $P$-value of $<0.05$ was considered statistically significant. Bonferroni correction was not performed because this was a hypothesis-generating study, the purpose of which was to identify a possible association between variables. Intraclass correlation coefficients were calculated by ICC function in psych $\mathrm{R}$ package.

\section{Results}

A total of 21 eyes of 21 patients with chronic CSC were studied (male eyes 14 , mean age $59 \pm 8.0$ years). Two patients were with drusen and 1 patient with ERM. There was no patient with high myopia or other retinal diseases. Fifteen patients received half-fluence PDT and 6 received half-dose PDT. The mean spot size was $2,977 \mu \mathrm{m}$ with a range from 1,400 to $4,500 \mu \mathrm{m}$.

SRD was resolved completely after 1 month in 12 eyes and after 3 months in 5 eyes, with $17(81 \%)$ of the eyes showing complete reabsorption. The remaining 4 eyes had persistent SRD throughout the follow-up period: 2 showed a decrease, but the other 2 were unchanged. No patients developed systemic side effects related to PDT, and neither RPE atrophy nor development of CNV was observed. The mean logMAR BCVA was 0.18 (0.66), 0.19 (0.64), 0.13 (0.74) and $0.12(0.76)$ before PDT and at 1, 3 and 6 months after PDT, respectively. Compared with baseline, a significant BCVA improvement was seen at 3 and 6 months after treatment ( $P=0.0045,0.0020$, respectively, paired $t$-test).

Retinal sublayer thickness was measured by 2 independent ophthalmologists, and the repeatability of the measurement was high, as evaluated by intraclass and interclass repeatability (Table 1). At 1, 3 and 6 months after PDT, the mean IFT was not significantly different from that before PDT (Table 2, $P=0.30,0.22$ and 0.22 , respectively, paired $t$-test; Figure 3). However, the mean PROS length of the irradiated area at 1 month after PDT was thinner than that before (Table 3, $P=0.020$, paired $t$-test); although at 3 and 6 months, there was no significant difference compared with that before PDT (Table 3, $P=0.53,1.00$, paired $t$-test; Figure 4). The same result was derived in half-fluence PDT group, and there was a similar trend in half-dose PDT group (Table 4). The mean PROS length of the nonirradiated area at 1, 3 and 6 months after PDT was not significantly different from that before PDT (Table 3, $P=0.66,0.90$, and 0.60 , respectively, paired $t$-test; Figure 5). The mean CT measured at 3 sections at 1, 3 and 6 months after PDT is listed in Table 5. At all time points, the mean $\mathrm{CT}$ of all 3 sections was significantly thinner than that before PDT $(P<0.001$, paired $t$-test $)$.

\section{Discussion}

This retrospective study suggests that PDT induces temporary micro-morphological changes in photoreceptors. The PROS length of the irradiated area was significantly thinner at 1 month after PDT than that before PDT, but it recovered to 

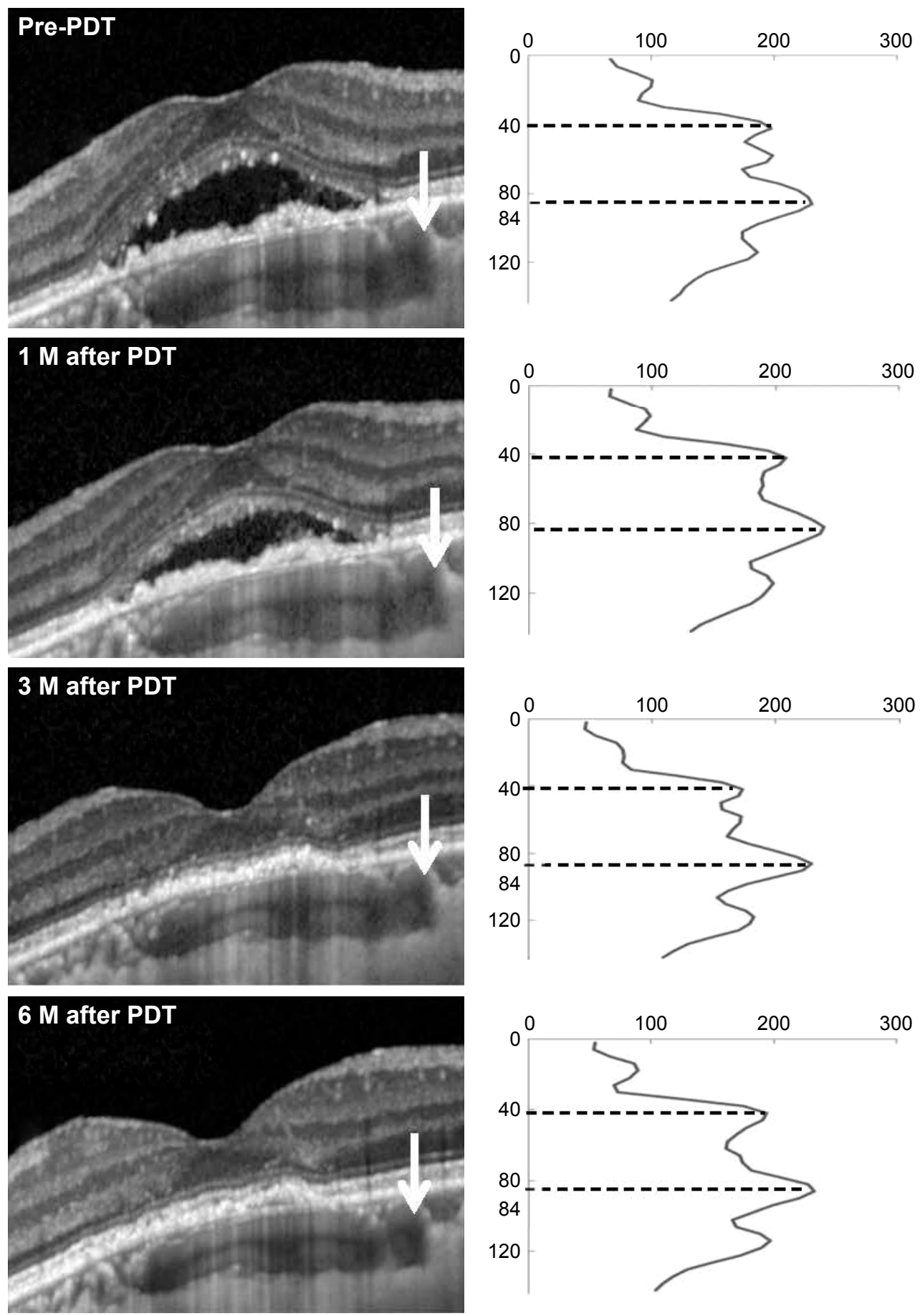

Figure 2 A representative case with chronic CSC.

Notes: A 60-year-old woman received half-fluence PDT and was followed for 6 months. Right columns show reflectivity profile which was calculated from spectral-domain optical coherence tomography images on the left side. A horizontal axis shows reflectivity, and the second and last distinct peaks represent the EZ line and RPE, respectively. Photoreceptor outer segment length was calculated from the distance between EZ and RPE. White arrows indicate the measurement points. Measurements were performed within the irradiated area but there was no existence of subnucleus reticularis dorsalis, and at the same points throughout the study.

Abbreviations: CSC, central serous chorioretinopathy; EZ, ellipsoid zone; M, months; PDT, photodynamic therapy; RPE, retinal pigment epithelium.

the baseline level at 3 and 6 months after PDT. In half-dose PDT, PROS length tended to become shorter at 1 month, although not significant due to small sample size (6 eyes). In contrast, the PROS length of the nonirradiated area did not differ from that before PDT at each time point examined.
This temporal change in photoreceptors could have been a direct or secondary effect of modified PDT.

In this study, we were able to detect significant shortening of PROS length at 1 month after PDT. There is conflicting evidence about the influence of PDT on photoreceptors. 
Table I Repeatability for inner foveal thickness, PROS length and choroidal thickness in CSC obtained using SD-OCT $(n=2 \mathrm{I})$

\begin{tabular}{lll}
\hline & \multicolumn{2}{l}{$\begin{array}{l}\text { Intraclass correlation coefficient } \\
(\mathbf{9 5 \%} \mathbf{C l})\end{array}$} \\
\cline { 2 - 3 } & $\begin{array}{l}\text { Intraclass } \\
\text { repeatability }\end{array}$ & $\begin{array}{l}\text { Interclass } \\
\text { repeatability }\end{array}$ \\
\hline Inner foveal thickness & $0.99(0.98,0.99)$ & $0.99(0.99,0.99)$ \\
PROS length & $0.92(0.82,0.96)$ & $0.90(0.78,0.96)$ \\
Choroidal thickness & $0.72(0.44,0.88)$ & $0.83(0.58,0.93)$ \\
\hline
\end{tabular}

Abbreviations: CSC, central serous chorioretinopathy; PROS, photoreceptor outer segment; SD-OCT, spectral-domain optical coherence tomography.

Schlötzer-Schrehardt et al reported that the overlying RPE and sensory retina were preserved in histopathological analysis 1 week after PDT, suggesting no subacute retinal or RPE damage after PDT. ${ }^{22}$ However, no histological study has yet investigated changes to photoreceptors 1 month after PDT. We hypothesize that this change occurs later than 1 week after PDT or that the histological changes are minute since the change in length, although significant, was only $3.1 \mu \mathrm{m}$. Indeed, the current method may be able to detect minute changes compared with histological analysis. For example, Yuksel et al also reported the significant changes in PROS length after ERM surgery, although the changes were just $2.9 \mu \mathrm{m}$ at a minimum. ${ }^{26}$

There are 3 possible explanations for the temporal shortening of PROS after PDT: hypoperfusion of choriocapillaris, a temporal increase of exudation after PDT and a direct effect by PDT. First, it may have been a secondary effect of collateral choroidal damage. The effect of PDT on choriocapillaris has been reported in both pathological and ICGA examinations. Schlötzer-Schrehardt et al detected choriocapillaris occlusion in the region of PDT application 1 week after standard PDT in human eyes by histopathological analysis. ${ }^{22}$ They also demonstrated the existence of repair mechanisms through observations of surviving endothelial cells, which indicated choriocapillaris recanalization as soon as 1 week after treatment. In the untreated area, choriocapillary structure was normal with open lumina. Schmidt-Erfurth et al later reported choroidal hypofluorescence in the treated area, the severity of which was most intense 1 week after PDT,

Table 2 Changes in inner foveal thickness after PDT $(n=2 I)$

\begin{tabular}{lllll}
\hline & \multicolumn{4}{l}{ Mean inner foveal thickness \pm SD $(\mu \mathrm{m})$} \\
\cline { 2 - 5 } & Pre-PDT & $\begin{array}{l}\text { I month } \\
\text { post-PDT }\end{array}$ & $\begin{array}{l}\text { 3 months } \\
\text { post-PDT }\end{array}$ & $\begin{array}{l}\text { 6 months } \\
\text { post-PDT }\end{array}$ \\
\hline & & $91.0 \pm 40.6$ & $92.4 \pm 42.3$ & $93.0 \pm 42.5$ \\
-value $^{\mathrm{a}}$ & & 0.30 & 0.22 & 0.22 \\
\hline
\end{tabular}

Note: aPaired $t$-test (compared with pre-PDT).

Abbreviation: PDT, photodynamic therapy.

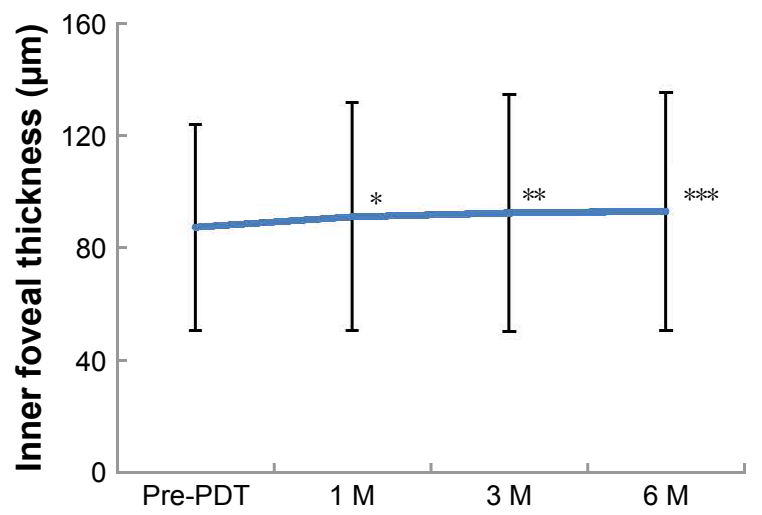

Figure 3 Serial changes in mean central IFT after half-fluence PDT in chronic central serous chorioretinopathy.

Notes: The mean IFT at I, 3 and 6 months after PDT was not significantly different from that before $(P=0.30 *, 0.22 * *$, and $0.22 * * *$, respectively, paired $t$-test). Bars show standard errors of the means.

Abbreviations: IFT, inner foveal thickness; M, months; PDT, photodynamic therapy.

with subsequent recovery of choroidal perfusion in ICGA findings. ${ }^{23}$ By means of ICGA, Reibaldi et al revealed that choriocapillaris at the site of PDT application was affected even by low-fluence PDT, although the intensity was less than that with standard PDT. ${ }^{14}$ Taken together, these findings suggest that in general, there is temporal choriocapillaris occlusion after PDT. Since the nutrients from choroidal circulation are essential for photoreceptor maintenance, it is rational to consider such choriocapillaris hypoperfusion that might have affected photoreceptors. The second explanation is that these changes were related to a temporal increase in exudation after PDT. Previous studies uniformly agree that there is a temporal exacerbation of exudative change after PDT, which resolved as early as 1 week after PDT. ${ }^{27-29}$ It is also possible that this temporal exudation might have caused damage to the photoreceptors and contributed to the temporal reduction of PROS length. The final explanation is that PDT had a direct effect on photoreceptor cells through unknown mechanism(s).

We detected a temporal change in photoreceptors, but the influence on visual function has not been determined. Some reports suggest a high correlation between PROS length and

Table 3 Changes in PROS length after PDT $(n=21)$

\begin{tabular}{lllll}
\hline & \multicolumn{3}{l}{ Mean PROS length \pm SD $(\mu \mathrm{m})$} \\
\cline { 2 - 5 } & Pre-PDT & $\begin{array}{l}\text { I month } \\
\text { post-PDT }\end{array}$ & $\begin{array}{l}\text { 3 months } \\
\text { post-PDT }\end{array}$ & $\begin{array}{l}\text { 6 months } \\
\text { post-PDT }\end{array}$ \\
\hline Irradiated area & $43.5 \pm 5.7$ & $40.4 \pm 7.5$ & $43.0 \pm 5.4$ & $43.5 \pm 4.3$ \\
-value $^{\mathrm{a}}$ & & 0.020 & 0.53 & 1.00 \\
Nonirradiated area & $41.8 \pm 6.4$ & $41.4 \pm 5.3$ & $42.0 \pm 4.7$ & $42.3 \pm 4.3$ \\
-value $^{\mathrm{a}}$ & & 0.66 & 0.90 & 0.60 \\
\hline
\end{tabular}

Note: ${ }^{\text {PPaired }} t$-test (compared with pre-PDT).

Abbreviations: PDT, photodynamic therapy; PROS, photoreceptor outer segment. 


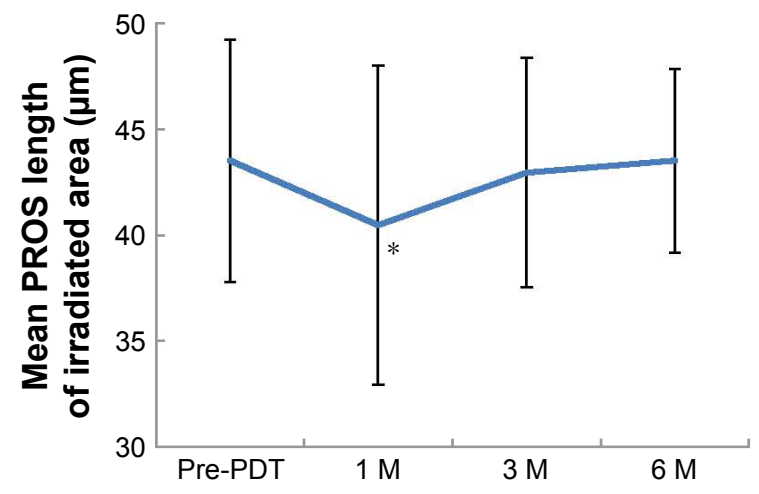

Figure 4 Serial changes in mean PROS length of the irradiated area after halffluence PDT in chronic central serous chorioretinopathy.

Notes: The mean PROS length at I month was less than that before PDT $\left(P=0.020^{*}\right.$, paired $t$-test); however, at 3 and 6 months, there was no significant difference compared with that before PDT $(P=0.52,1.00$, respectively, paired $t$-test). Bars show standard errors of the means.

Abbreviations: M, months; PDT, photodynamic therapy; PROS, photoreceptor outer segment.

BCVA. Shiono et al demonstrated a significant correlation between postoperative PROS length and BCVA in patients with a removed ERM, particularly at the central region. ${ }^{21}$ Forooghian et al also reported a strong correlation between foveal PROS length and BCVA in patients with diabetic macular edema. ${ }^{20}$ These findings support the fact that the central PROS length is a quantitative and important parameter of visual function. However, we did not assess the correlation between PROS length and BCVA. One reason for this was the relatively small number of investigated eyes, but more importantly, the measurements were taken outside the fovea to avoid the area of SRD. Therefore, it deemed unsuitable to assess the relationship between retinal function and the temporal changes in PROS length after PDT.

Several studies have assessed retinal function after PDT by evaluating retinal sensitivity using microperimetry. Fujita et al evaluated retinal sensitivity in central $4^{\circ}, 8^{\circ}$ and $12^{\circ}$ circles in chronic CSC, revealing significant improvements at 1,3 and 6 months after half-dose PDT at all sites. ${ }^{30}$ Senturk

Table 4 Changes in PROS length after PDT in irradiated area in half-fluence and half-dose groups

\begin{tabular}{|c|c|c|c|c|}
\hline & \multicolumn{4}{|c|}{ Mean PROS length \pm SD $(\mu \mathrm{m})$} \\
\hline & Pre-PDT & $\begin{array}{l}\text { I month } \\
\text { post-PDT }\end{array}$ & $\begin{array}{l}3 \text { months } \\
\text { post-PDT }\end{array}$ & $\begin{array}{l}6 \text { months } \\
\text { post-PDT }\end{array}$ \\
\hline $\begin{array}{l}\text { Half-fluence } \\
\text { group }(n=15)\end{array}$ & $42.8 \pm 6.0$ & $38.9 \pm 8.0$ & $42.8 \pm 5.2$ & $43.6 \pm 4.2$ \\
\hline$P$-value ${ }^{\mathrm{a}}$ & & 0.033 & 1.00 & 0.44 \\
\hline $\begin{array}{l}\text { Half-dose } \\
\text { group }(n=6)\end{array}$ & $45.3 \pm 4.8$ & $44.3 \pm 4.8$ & $43.3 \pm 6.4$ & $43.3 \pm 5.1$ \\
\hline$P$-value ${ }^{\mathrm{a}}$ & & 0.20 & 0.11 & 0.23 \\
\hline
\end{tabular}

Note: aPaired $t$-test (compared with pre-PDT).

Abbreviations: PDT, photodynamic therapy; PROS, photoreceptor outer segment.

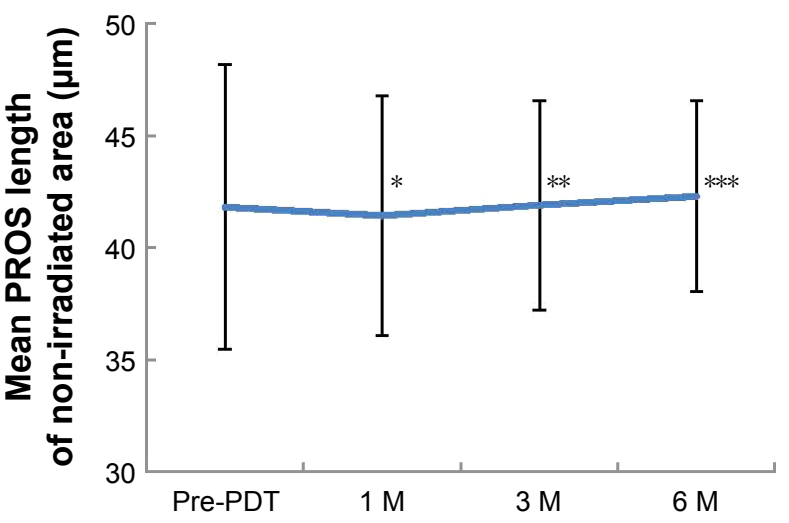

Figure 5 Serial changes in mean PROS length of nonirradiated area after half-fluence PDT in chronic central serous chorioretinopathy.

Notes: The mean PROS length of the nonirradiated area at I, 3 and 6 months after PDT did not significantly differ from that before $(P=0.66 *, 0.90 * *$, and $0.60 * * *$, respectively, paired $t$-test). Bars show standard errors of the means.

Abbreviations: M, months; PDT, photodynamic therapy; PROS, photoreceptor outer segment.

et al also examined retinal sensitivity in central $10^{\circ}, 20^{\circ}$, and paracentral $10^{\circ}$ to $20^{\circ}$ sites, revealing significant improvements at 1, 3 and 6 months after half-dose PDT in eyes with chronic CSC. ${ }^{31}$ Multifocal electroretinogram (mfERG) has also been utilized to evaluate retinal function after PDT. In contrast to the microperimetric studies, Lai et al detected a transient reduction in response amplitudes and a delay in peak latencies of mfERG for as long as 2 weeks, and recovery 1 month after PDT in patients with CNV. ${ }^{11}$ Overall, electrophysiological and current SD-OCT studies indicate temporal retinal damage after PDT, while microperimetric results show improved retinal function. It is not surprising that the retinal function improves after the absorption of SRF as has been reported by previous studies. These apparently discordant functional findings from previous studies may be due to the difference in the baseline visual function, the irradiation area, the size of SRF and chronicity of the disease. The current cases were with relatively good visual acuity and no signs of chronicity such as atrophic tract (or gravitational tract).

With regard to $\mathrm{CT}$, our results concur with those of previous investigations. We also evaluated choroidal changes after

Table 5 Changes in choroidal thickness after PDT $(n=2 I)$

\begin{tabular}{llll} 
Mean choroidal thickness \pm SD $(\mu \mathrm{m})$ \\
\hline Pre-PDT & $\begin{array}{l}\text { I month } \\
\text { post-PDT }\end{array}$ & $\begin{array}{l}3 \text { months } \\
\text { post-PDT }\end{array}$ & $\begin{array}{l}\mathbf{6} \text { months } \\
\text { post-PDT }\end{array}$ \\
\hline $403 \pm 135$ & $358 \pm 139^{\mathrm{a}}$ & $332 \pm 122^{\mathrm{a}}$ & $325 \pm 117^{\mathrm{a}}$ \\
$382 \pm 114$ & $340 \pm 117^{\mathrm{a}}$ & $320 \pm 112^{\mathrm{a}}$ & $321 \pm 113^{\mathrm{a}}$ \\
$297 \pm 126$ & $260 \pm 110^{\mathrm{a}}$ & $264 \pm 110^{\mathrm{a}}$ & $259 \pm 109^{\mathrm{a}}$ \\
\hline
\end{tabular}

Note: ${ }^{a}<0.001$ (paired $t$-test, compared with pre-PDT).

Abbreviation: PDT, photodynamic therapy. 
PDT for chronic CSC using SD-OCT at 3 sections: 2 within the irradiated area and 1 in the nonirradiated area. A reduction in CT was observed in all areas. Sugano et al also reported a reduction in CT after PDT for PCV outside the irradiated area. ${ }^{32}$ Our results are compatible with previous reports of the effect of PDT on the choroid even in the area not exposed to PDT laser treatment.

Finally, our findings also showed that the mean IFT at 1,3 and 6 months after PDT did not differ significantly from that before PDT; however, there was a tendency toward increased IFT at 1 month after PDT. The most probable cause of this can be due to improved metabolism of photoreceptors in the fovea after reattachment to RPE, or a decrease in physical pressure on the photoreceptors as a result of resolution of SRF.

Analytic software of SD-OCT has been improving and Spectralis is equipped with new software that can finely segment each retinal layer and measure each layer's thickness automatically. In normal eyes, this measuring method may be quite accurate, but if there are lesions such as SRF, and/or pigment epithelial detachment, automated segmentation sometimes fails to recognize ELM, EZ, RPE and Bruch membrane correctly, thus requiring manual correction. Although Image J uses manual measurement, it is most useful in the analysis of the outer retinal thickness. ${ }^{33,34} \mathrm{We}$ still assume this to be one of the most accurate measurements at the moment.

Despite the significant findings, our study is limited by its retrospective design. The number of investigated eyes was relatively small, and the follow-up period was relatively short. Further prospective studies with large numbers are therefore needed to confirm our results. Other limitations were the lack of evaluation at the early phase within 1-2 weeks after PDT and insufficient evaluation of retinal function. Analysis of sequence changes in the retina after PDT are therefore required both morphologically and functionally, allowing us to determine the mechanism of temporal impairment of the retina induced by PDT. Our study showed that a total of 17 of 21 eyes $(81 \%)$ had complete reabsorption at 6 months. In contrast, Fujita et al studied totally 204 eyes with chronic CSC and reported 182 eyes (89\%) with resolution of SRD at 12 months after the half-dose PDT. ${ }^{35}$ Our treatment outcome seems slightly poor, but direct comparison is meaningless because of the differences of the follow-up period and studied subjects.

In conclusion, our findings showed mild outer retinal microstructural changes 1 month after modified PDT, with recovery at 3 and 6 months. The changes were short-lived and of uncertain clinical significance; however, it should be noted that we assessed patients with a single PDT application. There is a possibility that irreversible impairment to the retina may occur as a result of multiple PDT applications, especially when full-dose PDT is employed. Further observations and clinical trials are therefore needed to assess the effect of PDT on photoreceptor and retinal function.

\section{Disclosure}

The authors report no conflicts of interest in this work.

\section{References}

1. Prunte C, Flammer J. Choroidal capillary and venous congestion in central serous chorioretinopathy. Am J Ophthalmol. 1996;121(1): 26-34.

2. Piccolino FC, Borgia L. Central serous chorioretinopathy and indocyanine green angiography. Retina. 1994;14(3):231-242.

3. Guyer DR, Yannuzzi LA, Slakter JS, Sorenson JA, Ho A, Orlock D. Digital indocyanine green videoangiography of central serous chorioretinopathy. Archs Ophthalmol. 1994;112(8):1057-1062.

4. Levine R, Brucker AJ, Robinson F. Long-term follow-up of idiopathic central serous chorioretinopathy by fluorescein angiography. Ophthalmology. 1984;91:1544-1548.

5. Loo RH, Scott IU, Flynn HW Jr, et al. Factors associated with reduced visual acuity during long-term follow-up of patients with idiopathic central serous chorioretinopathy. Retina. 2002;22(1):19-24.

6. Erol MK, Balkarli A, Toslak D, et al. Evaluation of nailfold videocapillaroscopy in central serous chorioretinopathy. Graefe's Arch Clin Exp Ophthalmol. 2016;254(10):1889-1896.

7. Kloos P, Laube I, Thoelen A. Obstructive sleep apnea in patients with central serous chorioretinopathy. Graefe's Arch Clin Exp Ophthalmol. 2008;246(9):1225-1228.

8. Chan WM, Lam DS, Lai TY, Tam BS, Liu DT, Chan CK. Choroidal vascular remodeling in central serous chorioretinopathy after indocyanine green guided photodynamic therapy with verteporfin: a novel treatment at the primary disease level. Br J Ophthalmol. 2003;87(12): 1453-1458.

9. Ficker L, Vafidis G, While A, Leaver P. Long-term follow-up of a prospective trial of argon laser photocoagulation in the treatment of central serous retinopathy. Br J Ophthalmol. 1988;72(11):829-834.

10. Cardillo Piccolino F, Eandi CM, Ventre L, Rigault de la Longrais RC, Grignolo FM. Photodynamic therapy for chronic central serous chorioretinopathy. Retina. 2003;23(6):752-763.

11. Lai TY, Chan WM, Lam DS. Transient reduction in retinal function revealed by multifocal electroretinogram after photodynamic therapy. Am J Ophthalmol. 2004;137(5):826-833.

12. Tzekov R, Lin T, Zhang KM, et al. Ocular changes after photodynamic therapy. Invest Ophthalmol Vis Sci. 2006;47(1):377-385.

13. Chan WM, Lai TY, Lai RY, Tang EW, Liu DT, Lam DS. Safety enhanced photodynamic therapy for chronic central serous chorioretinopathy: oneyear results of a prospective study. Retina. 2008;28(1):85-93.

14. Reibaldi M, Cardascia N, Longo A, et al. Standard-fluence versus low-fluence photodynamic therapy in chronic central serous chorioretinopathy: a nonrandomized clinical trial. Am JOphthalmol. 2010; 149(2):307-315.

15. Hernandez G, Carlos J, Camarillo M, Sadda SR. Long-term follow-up of photoreceptor loss and recovery after half-fluence photodynamic therapy for chronic central serous chorioretinopathy. Retin Cases Brief Rep. 2015;9(2):109-113.

16. Ratanasukon M, Thongthong K, Bhurayanontachai P, Jirarattanasopa P. Photoreceptor disruption in central serous chorioretinopathy treated by half-dose photodynamic therapy. Clinl Ophthalmol. 2013;7:87-92.

17. Matsumoto H, Kishi S, Otani T, Sato T. Elongation of photoreceptor outer segment in central serous chorioretinopathy. Am J Ophthalmol. 2008;145(1):162-168. 
18. Park SJ, Woo SJ, Park KH, Hwang JM, Chung H. Morphologic photoreceptor abnormality in occult macular dystrophy on spectral-domain optical coherence tomography. Invest Ophthalmol Vis Sci. 2010;51(7): 3673-3679.

19. Itoh Y, Inoue M, Rii T, Hiraoka T, Hirakata A. Significant correlation between visual acuity and recovery of foveal cone microstructures after macular hole surgery. Am J Ophthalmol. 2012;153(1):111.e1-119.e1.

20. Forooghian F, Stetson PF, Meyer SA, et al. Relationship between photoreceptor outer segment length and visual acuity in diabetic macular edema. Retina. 2010;30(1):63-70.

21. Shiono A, Kogo J, Klose G, et al. Photoreceptor outer segment length: a prognostic factor for idiopathic epiretinal membrane surgery. Ophthalmology. 2013;120(4):788-794.

22. Schlotzer-Schrehardt U, Viestenz A, Naumann GO, Laqua H, Michels S, Schmidt-Erfurth U. Dose-related structural effects of photodynamic therapy on choroidal and retinal structures of human eyes. Graefe's Arch Clin Exp Ophthalmol. 2002;240(9):748-757.

23. Schmidt-Erfurth U, Michels S, Barbazetto I, Laqua H. Photodynamic effects on choroidal neovascularization and physiological choroid. Invest Ophthalmol Vis Sci. 2002;43(3):830-841.

24. Maruko I, Iida T, Sugano Y, Ojima A, Ogasawara M, Spaide RF. Subfoveal choroidal thickness after treatment of central serous chorioretinopathy. Ophthalmology. 2010;117(9):1792-1799.

25. Kang NH, Kim YT. Change in subfoveal choroidal thickness in central serous chorioretinopathy following spontaneous resolution and lowfluence photodynamic therapy. Eye. 2013;27(3):387-391.

26. Yuksel K, Karakucuk Y, Ozkaya A, et al. Comparison of photoreceptor outer segment length in diabetic and idiopathic epiretinal membranes. Eye. 2015;29(11):1446-1452.

27. Rogers AH, Martidis A, Greenberg PB, Puliafito CA. Optical coherence tomography findings following photodynamic therapy of choroidal neovascularization. Am J Ophthalmol. 2002;134(4):566-576.
28. Costa RA, Farah ME, Cardillo JA, Calucci D, Williams GA. Immediate indocyanine green angiography and optical coherence tomography evaluation after photodynamic therapy for subfoveal choroidal neovascularization. Retina. 2003;23(2):159-165.

29. Michels S, Schmidt-Erfurth U. Sequence of early vascular events after photodynamic therapy. Invest Ophthalmol Vis Sci. 2003;44(5): 2147-2154.

30. Fujita K, Shinoda K, Matsumoto CS, et al. Microperimetric evaluation of chronic central serous chorioretinopathy after half-dose photodynamic therapy. Clin Ophthalmol. 2012;6:1681-1687.

31. Senturk F, Karacorlu M, Ozdemir H, Karacorlu SA, Uysal O. Microperimetric changes after photodynamic therapy for central serous chorioretinopathy. Am J Ophthalmol. 2011;151(2):303.e1-309.e1.

32. Sugano Y, Iida T, Maruko I, Ojima A, Sekiryu T. Choroidal thickness outside the laser irradiation area after photodynamic therapy in polypoidal choroidal vasculopathy. Jpn J Ophthalmol. 2013;57(3): 294-300.

33. Chen H, Xia H, Qiu Z, Chen W, Chen X. Correlation of optical intensity on optical coherence tomography and visual outcome in central retinal artery occlusion. Retina. 2016;36(10):1964-1970.

34. Ichiyama Y, Kawamura H, Fujikawa M, Sawada O, Saishin Y, Ohji M. Photoreceptor outer segment length and outer foveal thickness as factors associated with visual outcome after vitrectomy for vitreomacular traction syndrome. Retina. 2016;36(9):1707-1712.

35. Fujita K, Imamura Y, Shinoda K, et al. One-year outcomes with halfdose verteporfin photodynamic therapy for chronic central serous chorioretinopathy. Ophthalmology. 2015;122(3):555-561.
Clinical Ophthalmology

\section{Publish your work in this journal}

Clinical Ophthalmology is an international, peer-reviewed journal covering all subspecialties within ophthalmology. Key topics include: Optometry; Visual science; Pharmacology and drug therapy in eye diseases; Basic Sciences; Primary and Secondary eye care; Patient Safety and Quality of Care Improvements. This journal is indexed on

\section{Dovepress}

PubMed Central and CAS, and is the official journal of The Society of Clinical Ophthalmology (SCO). The manuscript management system is completely online and includes a very quick and fair peer-review system, which is all easy to use. Visit http://www.dovepress.com/ testimonials.php to read real quotes from published authors. 